\title{
PETICIÓN DE SIMPATÍA PARA LOS NEOLIBERALES DE IZQUIERDA ARREPENTIDOS
}

James Bradford DeLong*

$\mathrm{C}$ omo siempre, cuando el sumamente agudo Dani Rodrik mete un argumento que tendría la longitud de un libro en una columna de opinión de 800 palabras, las frases aluden a lo que propiamente son argumentos que llenarían un capítulo. De modo que hay mucho de qué hablar.

\section{En "La abdicación de la izquierda", Dani Rodrik dice":}

La híper globalización del comercio y las finanzas, que pretendía crear mercados mundiales perfectamente integrados, desgarró a las sociedades domésticas. La mayor sorpresa es la clara inclinación derechista de la reacción política. En Europa son ante todo los nacionalistas y populistas localistas los que han ganado protagonismo, mientras que la izquierda solo ha avanzado en pocos lugares, como Grecia y España [...] Como reconoce a regañadientes el nuevo consenso emergente del establecimiento, la globalización acentúa las divisiones de clase, entre quienes tienen las habilidades y los recursos para sacar ventaja de los mercados internacionales y quienes no los tienen. Las divisiones de ingreso y de clase, en contraste con las divisiones de identidad basadas en la raza, la etnia o la religión, tradicionalmente han fortalecido a la izquierda política. ¿Por qué esta ha sido incapaz de organizar un fuerte desafío político a la globalización?

Pienso que ese párrafo es en gran parte erróneo.

Como el muy perspicaz Patrick Iber escribió en Twitter, la respuesta usual a la angustia económica en las democracias con amplias licencias es: “¡Echar a los bastardos!”. Consideremos la Gran Depre-

* Profesor de Economía, Universidad de California, Berkeley, Estados Unidos, [delong@econ.berkeley.edu]. Nota tomada de DeLong: Long Form, 11 de julio de 2016, [http://delong.typepad.com/delong_long_form/]. Traducción de Alberto Supelano. Se publica con autorización del autor. Fecha de recepción: 21-07-2016, fecha de aceptación: 20-10-2016. Sugerencia de citación: Bradford D., J. "Petición de simpatía para los neoliberales de izquierda arrepentidos", Revista de Economía Institucional 18, 35, 2016, pp. 307-312. Dor: http://dx.doi.org/10.18601/01245996. v18n35.17.

1 Publicado en Project Syndicate, 11 de julio de 2016. Ver la traducción al español en este número de REI, Rodrik (2016, 303-306) [Nota del editor]. 
sión. E1 laborismo cayó en Gran Bretaña en 1931. Los republicanos cayeron en Estados Unidos en 1932. Y en Alemania... el horror. Y hoy, un siglo y dos tercios después de que Alexis de Tocqueville escribiera en sus Recuerdos de la revolución de 1848:

Escuché un sonido metálico y seco, que hizo temblar nuestros cristales y se
extinguió inmediatamente, en medio del silencio de París. “¿Qué es eso?" -
dije-. Y mi mujer me respondió: "Son cañonazos. Hace una hora que los estoy
oyendo, pero no he querido despertarte, porque hoy necesitarás, seguramente,
todas tus fuerzas". Me vestí de prisa...

Entraban entonces en la ciudad millares de hombres que acudían desde todos los puntos de Francia en nuestra ayuda. Gracias a los ferrocarriles, venían ya desde cincuenta leguas, a pesar de que la lucha no había comenzado hasta la víspera por la tarde. Y vinieron de cien y de doscientas leguas, al día siguiente y en días sucesivos. Aquellos hombres pertenecían, indistintamente, a todas las clases de la sociedad, y había entre ellos muchos campesinos, muchos burgueses, muchos grandes propietarios y nobles, todos mezclados y confundidos en las mismas filas. Estaban armados, de una manera irregular e insuficiente, pero corrían hacia París con un entusiasmo sin igual: un espectáculo tan extraño y tan nuevo en nuestros anales revolucionarios como el ofrecido por la propia insurrección. Era evidente, desde aquel momento, que nosotros acabaríamos triunfando, porque los insurgentes no recibían tropas de refresco, y nosotros teníamos como reserva a toda Francia.

En la plaza de Luis xv, encontré, en medio de los habitantes armados de su cantón, a mi pariente Lepelletier d'Aunay, que había sido vicepresidente de la Cámara de los diputados durante los últimos años de la monarquía. No llevaba uniforme ni mosquete: sólo un espadín de ceremonia, con el puño de plata, que había colgado al cinto, por encima de su traje, con ayuda de una estrecha bandolera de tela blanca.

Me emocioné hasta las lágrimas, al ver a aquel hombre respetable y de cabellos blancos, tan grotescamente vestido. “¿No quieres comer hoy en mi casa?" — le dije-. "No — me respondió-. ¿Qué dirían estos valientes que me acompañan y que saben que yo tengo mucho más que perder que ellos con el triunfo de la insurrección, si me ven que les dejo así para ir a disfrutar de mis comodidades? No, yo compartiré lo que ellos coman y me acostaré aquí, en su vivac. Lo único que te pido es que aceleres un poco, si te es posible, el envío del pan de munición que nos han prometido, porque estamos sin comer desde esta mañana".

En junio de 1849 la insurrección del proletariado urbano de París impulsada por la depresión fue suprimida sangrientamente por una movilización masiva, en gran parte espontánea, de gentes de la Isla de Francia que pensaban que tenían algo que perder con la revolución. Imaginaban que las pocas propiedades que tenían serían confiscadas y distribuidas a los holgazanes desempleados de la ciudad, a las "clases peligrosas” urbanas. Que podrían ser gravados para pagar la reapertura de los Talleres Nacionales que garantizarían el empleo a quienes no podían encontrar otros trabajos. Que podrían empeorar: sus amigos arrestados por insuficiente entusiasmo por la revolución, sin sus sacerdotes y sin sus esperanzas de ir al cielo. Por todas esas razones 
se inclinaron a la derecha, votaron en favor de una mano autoritaria nacionalista firme en el gobierno, y votaron por Luis Bonaparte, primero como presidente de la Segunda República Francesa, y luego como Emperador Napoleón iII del Segundo Imperio Francés.

Creo que en general es errónea la creencia de que la angustia económica desplaza la política democrática hacia la izquierda. Lleva a que la política democrática se distancie del establecimiento, sea cual sea el establecimiento. Puede inclinarse a la izquierda -como en los Estados Unidos de Franklin Delano Roosevelt y en la Francia de León Blum y el Frente Popular. Puede inclinarse a la derecha-como en Francia en 1849 y en los primeros tiempos de la Gran Depresión, como en Gran Bretaña en 1931 y 2010, y en Estados Unidos en 2010, y como en, humm, Alemania.

\section{Dani continúa:}

Una respuesta es que la inmigración ha eclipsado otros "choques" de la globalización [...] Las democracias latinoamericanas proporcionan un contraste elocuente. Estos países experimentaron la globalización ante todo como un choque comercial y de inversión extranjera, y no como un choque de inmigración. La globalización se convirtió en sinónimo de las políticas del Consenso de Washington y de apertura financiera. La inmigración proveniente de Oriente Medio o África siguió siendo reducida y tenía poca importancia política. De modo que la reacción populista en América Latina -en Brasil, Bolivia, Ecuador y, más desastrosamente, en Venezuela- fue de carácter izquierdista.

No: como dije, contraria al establecimiento. En América Latina, el establecimiento acogió el Consenso de Washington, relativamente de centro-derecha. En Europa, en casi todo el continente, el establecimiento acogió el mercado social, relativamente de centro-izquierda. Solo allí donde, como dice Dani, se percibe que el establecimiento europeo gira en torno al ordoliberalismo de Berlín y no en torno al mercado social de Bruselas hay espacio para que la angustia impulse la política hacia la izquierda.

Pienso, entonces, que Dani toma firmemente el hilo correcto:

Una mayor debilidad de la izquierda: la falta de un programa claro para remodelar el capitalismo y la globalización en el siglo xxI [...] la izquierda no ha logrado proponer ideas económicamente sólidas y políticamente populares, más allá de políticas de mejoramiento como las transferencias de ingresos.

A los economistas y tecnócratas de izquierda les corresponde gran parte de la culpa. En vez de contribuir a elaborar dicho programa, abdicaron con demasiada facilidad ante el fundamentalismo de mercado y aceptaron sus postulados centrales.

En retrospectiva, ¿quién puede estar en desacuerdo? Juzgamos mal el balance adecuado entre Estado y mercado, entre las vías del man- 
dato y el control y de los incentivos de mercado hacia fines sociales democráticos.

Pero, entonces, de nuevo debo disentir en parte. Dice Dani:

Peor aún, [los economistas y tecnócratas de izquierda] lideraron el movimiento híper globalización en coyunturas cruciales.

La entronización de la libre movilidad del capital -en especial del capital de corto plazo- como norma de política de la Unión Europea, la ocDE y el FMI fue sin duda la decisión más fatídica para la economía global de las últimas décadas. Como mostró el profesor de la Escuela de Negocios de Harvard Rawi Abdelal, este esfuerzo fue encabezado, a finales de los ochenta y comienzos de los noventa, no por ideólogos del mercado libre sino por tecnócratas franceses como Jacques Delors (en la Comisión Europea) y Henri Chavranski (en la OCDE), asociados estrechamente al partido socialista de Francia. De igual modo, en Estados Unidos, fueron tecnócratas asociados al partido demócrata más keynesiano, como Lawrence Summers, quienes dirigieron la carga para la desregulación financiera $[\ldots]$

Los tecnócratas socialistas de Francia parecen haber concluido que el manejo económico local ya no era posible, y que no había ninguna alternativa real a la globalización financiera. Lo mejor que se podía hacer era promulgar normas a nivel europeo y mundial, en vez de permitir que países poderosos como Alemania o Estados Unidos impusieran las suyas.

Y aquí me lamento. La globalización financiera pretendía eliminar las barreras a la entrada de capitales levantadas por cazadores de rentas en los países en desarrollo, y acelerar así el crecimiento de las economías carentes de capital al tiempo que se igualaban los ingresos. Se suponía que la desregulación financiera quebrantaría el círculo cerrado de la banca de inversión y otras oligarquías de Wall Street y disminuiría su gravamen al sector privado de la economía estadounidense. Se suponía que la desregulación financiera proporcionaría, a la mitad más pobre de Estados Unidos, acceso a un precio razonable al crédito del que carecía y la oportunidad de invertir en activos que produjeran rendimientos aceptables, de los que también carecía. Y, en un mundo en que los bancos centrales tenían las facultades y la voluntad para estabilizar la demanda agregada, no parecía inconveniente dejar que la gente que no podía reunir el $20 \%$ de la cuota inicial para comprar una casa, se obligara a Morgan Stanley y Goldman Sachs a enfrentar la competencia de Citigroup y Bank of America, y se permitiera que los empresarios de México recaudaran fondos no solamente entre la oligarquía cerrada de los bancos de Ciudad de México sino en el mercado mundial de capitales.

Y los tecnócratas socialistas de Francia tenían razón: en economías muy abiertas la tarea de manejar la demanda agregada debe ser global, o de la región del Atlántico Norte, o al menos un ejercicio continental. En un buen mundo, sólo debería haber grandes variaciones de la tasa 
de cambio en respuesta a desequilibrios fundamentales persistentes, en vez de usarlas como instrumento de primera mano para manejar la demanda.

Todo se hizo horriblemente mal. Pero restringir el mandato del все al mero control de la inflación nunca fue un artículo de política de la izquierda; y toda la izquierda supuso que los tecnócratas del все nо serían tan estúpidos como para considerar ese único mandato como algo más que palabrería para tranquilizar los mercados de bonos en los buenos tiempos. Y la decisión de que los bancos de dinero usaran los mercados de derivados no para diversificarse sino para concentrarse en el riesgo del precio de la vivienda en sus balances no se tomó a la vista del público.

Debo entonces disentir de nuevo. Pienso que el penúltimo párrafo de Dani es demasiado optimista:

La buena noticia es que el vacío intelectual de la izquierda se está llenando, y que ya no hay ninguna razón para creer en la tiranía de que no existe "ninguna alternativa". Los políticos de izquierda tienen cada vez menos razones para no recurrir a un "respetable" poder de fuego académico en economía.

Anat Admati y Simon Johnson han defendido reformas bancarias radicales; Thomas Piketty y Tony Atkinson han propuesto un amplio menú de políticas para enfrentar la desigualdad a nivel nacional; Mariana Mazzucato y Ha-Joon Chang han escrito lúcidamente sobre la manera de utilizar el sector público para fomentar la innovación inclusiva; Joseph Stiglitz y José Antonio Ocampo han propuesto reformas globales; Brad DeLong, Jeffrey Sachs y Lawrence Summers (¡él mismo!) han argumentado en favor de la inversión pública de largo plazo en infraestructura y en economía verde. Aquí hay suficientes elementos para elaborar una respuesta económica programática de la izquierda.

Aquí, en cambio, estoy de acuerdo, con algo que Keynes escribió en Trotsky sobre Inglaterra, publicado en marzo de 1926:

Todos los partidos políticos se originaron en ideas del pasado y no en ideas nuevas. Y muy notoriamente los partidos marxistas [...] nadie posee la verdad. Lo que hay que hacer es usar la inteligencia.

¡E1 problema es que nuestra agenda política actual es demasiado "hacerlo de nuevo"!, donde el "lo" es "keynesianismo, socialdemocracia, Estado de bienestar”. Y creo que necesitamos más. Pienso que Dani tiene razón cuando señala:

La derecha se nutre de la profundización de las divisiones en la sociedad - "nosotros" contra "ellos"- mientras que la izquierda, cuando tiene éxito, supera esas divisiones mediante reformas que las cierran.

Pero cuando dice:

Las primeras oleadas de reformas de la izquierda -keynesianismo, socialdemocracia, Estado de bienestar- salvaron al capitalismo de sí mismo y se volvieron superfluas... 
tiene razón y está equivocado: las primeras oleadas salvaron al capitalismo de sí mismo, pero solo se volvieron aparentemente superfluas durante los años de la Convergencia Global y los años de la Gran Moderación. No son superfluas. Las necesitamos. Y necesitamos más. Pues Dani tiene razón al concluir:

En ausencia de tal respuesta, el campo quedará abierto para que los grupos populistas y de extrema derecha lleven al mundo -como siempre lo han hecho- a divisiones más profundas y a conflictos más frecuentes. 